\title{
Morphological Rule Induction for Terminology Acquisition
}

\author{
Béatrice Daille \\ IRIN, 2, rue de la Houssinic̀re, I3P 92208, 44322 Nantes Cedex 3 France \\ daille@irin.univ-nantes.fi
}

\begin{abstract}
We present the identification in corpora of Fuench relational adjectives (RAdj) such as gazeux (gascous) which is derived from the nom gaz (gas). R.Adj appearing in nominal phrases are interesting for terminology acquisition because they hold a maming function. 'Tho derivational rules employed to compute the nom from which has been derived the $R \Lambda$ dj are acepuired semi-automatically from a tagged and a lemunatized corpora. These rules are then integrated into a termer which identifies RAdj thanks to their property of being paraphrasable by a prepositional phrase. R $\Lambda \mathrm{dj}$ and componnd nouns which include a RAdj are then quantified, their linguistic precision is moasured and their informative status is evaluated thanks to a thesaurus of the domain.
\end{abstract}

\section{Introduction}

Identifying relational adjectives ( $12 \Lambda \mathrm{dj})$ such as malarial, and nom phrases in which they appear such as malarial mosquitoes, could bo interesting in several fields of NLP, such as terminology acquisition, topic detection, npedating of thesauri, because they hold a naming function acknowledged by linguists: (Levi, 1978), (MćlisPuchululu, 1991), etc. The use of $R \Lambda$ dj is particularly frecuenti in scientific ficlds (Monceaux, 1993). Paradoxically, terminology acquisition systems such as TERMINO (David and Plante, 1990), LEXTER (Bourigault, 1992), TERMS (Justeson and Kat\%, 1995), have not been concorned with RAdj. Evon (Tbokwe-Sanjua, 1998) in her study of term variations for identifying rescarch topics from texts does not take into account derivational variants. Our concern is:

1. To identify noun phrases in which relational adjectives appear, as well as the prepo- sitional phrases by which they could be paraphrased. Wo will see through another source presented in section 2 that this property of paraphrase can be used to identify these adjectives.

2. To check the naming character of these adjectives and to evaluate the naming chatracter of the noun phrases in which they appear.

Moreover, idcentifying both the adjective and the prepositional phrase is useful in the field of terminology accuisition for performing accurate term normalization by grouping synonym forms referring to an unique concept such as produit laitier (dairy product) and, produit au lait (product with milk), produit de lait (product of milk), produit issu du lait (product made of milk), cte. To (arry ont this identification, wo use shallow parsing ( $A$ bney, 1991), and then, for mos:phological processing, a dynanic; method which takes as input a corpus labeled with part-ofspeech and lemma tags. The morphological rules are built semi-automatically from the corpuls.

In this study, we first define, and give some linguistic properties of RAdj. We then present the method to build morphological rules and how to integrate then into a term extractor. We quantify the results obtaincd from a technical corpus in the field of agriculture [AGRIC] and evaluate their linguistic and informative precision.

\section{Linguistic properties of relational adjectives}

According to linguistic and grammatical tradition, there are two main categories among adjectives: epithetic such as important (significant) and relational adjectives such as laitier (deiry). The first ones camnot have an agentive interpre- 
tation in contrast to the second: the adjective laitier (dairy) within the noun phrase production laitière (dairy production) is an argument to the predicative noun production (production) and this is not the case for the adjective important (significant) within the phrase production importante (significant production). Rolational adjectives (RAdj) possess the following wellknown linguistic properties:

- they are either denominal adjectives morphologically derived from a noun thanks to suffix-, or adjectives having a noun usage such as mathématique (mathematical/mathematics). For the former, not all the adjective-forming suffixes lead to relational adjectives. The following suffixes are considered by (Dubois, 1962) as appropriate:-ain, -aire, -al, -cl, -estre, ien, -ier, -ill(e), -in,-ique. However, (Guyon, 1993) remarks that a suffix, even the most appropriate, is never necessary nor sufficient. Several adjectives carrying a favorable suffix are not relational: this is the case with the adjoctives ending with -ique (-ic), which characterize chemistry and which are not derived from a noun, such as désoxyribonucléique (deoryribonucleic), dodecanoique (dodecanoic), etc. Other suffixes inappropriate are sometimes used such as the suffixes -é and -eux: carbone (carbon) $\rightarrow$ carboné (carbonaceous), cancer (cancer) $\rightarrow$ cancéreux (cancerous), etc.

- they own the possibility, in special conditions, of replacing the attributive use of a corresponding prepositional phrase. The preposition employed, as well as the presence or not of a determiner, depends on the head noun of the noun phrase:

acidité sanguine (blood acidity) $\simeq$ acidité du sang (acidity of the blood)

conquête spatiale (space conquest) $\simeq$ conquête de l'espace (conquest of space)

débit horaire (hourly rate) $\simeq$ débit par heure (rate per hour) expérimentations animales (animal experimentation $) \simeq$ cxpérimentations sur les animaux (experimentation on animals)

- and several other properties such the impossibility of a predicative position, the in- compatibility with a degree modification, etc.

\section{Morphological Rule Induction}

To identify RAdj trough a term extractor, we use their paraphrastic property which includes the morphological property, the morphological property being insufficient alone. We need rules to recover the lemma of the noun from which the lemma of the RAdj has been derived.

These rules follow the following schemata:

$\mathrm{R}=[-\mathrm{S}+\mathrm{M}]\{$ exceptions $\}$ where:

$\mathbf{S}$ is the relational suffix to be delcted from the end of an adjective. The result of this deletion is the stem $\mathbf{R}$;

$\mathrm{M}$ is the mutative segment to be concatenated to $\mathbf{R}$ in order to form a noun;

exceptions list the adjectives that should not be submitted to this rule.

For example, the rule $[-\dot{e}+e]\{$ agé $\}$ says that if there is an adjective which ends with $e$, wo should strip this ending from it and append the string $e$ to the stem except if this adjective belongs to the list of exceptions, namcly agé.

We extract these morphological rules from the corpora following the method presented in (Mikheev, 1997) with the difference that we don't limit the length of the mutative segment. The relational suffixes are known, only the mutative segments have to be guessed. For the lemma of an adjective ending with a relational suffix in the corpus $\operatorname{Adj}_{i}$, we strip this suffix of $\mathrm{Adj}_{i}$ and store the resulting stem in R. Then, we try to segment this stem $R$ to each noun Noun $_{j}$ appearing in the corpus. If the subtraction result in an non-empty string, the system creates a morphological rule where the mutative segment is the result of the subtraction of $\mathrm{R}$ to $\operatorname{Noun}_{j}$. We thus obtained couples (Adj ${ }_{i}$, $\operatorname{Noun}_{j}$ ) associated to a morphological rule. For example: (gazeux, gaz) [-cux +"'].

This schemata doesn't take into account stem alternants such as:

e/é alphabet/aphabét-ique

è/é hygiène/hygién-ique

e/i pollen/pollin-ique

$\mathrm{x} / \mathrm{c}$ thorax / thorac-ique 
In order to landle this allomorphy, we use the Levenshtein's weighted distance (Levenshtein, 1.966) which determines the minimum number of insertions or deletions of characters to transformone word into another. (Wagner and Fisher, 1974) presents a recursive algorithm to calculate: this distance.

$$
\begin{aligned}
\operatorname{dist}( & \left(w_{1, i}, w_{1, j}^{\prime}\right)= \\
& \min \left(\operatorname{dis} s t\left(w_{1, i-1}, w_{1, j}^{\prime}\right)+q\right. \\
& \left.\operatorname{dist}\left({ }_{u 1, i}, w_{1, j-1}^{\prime}\right)+q\right), \\
& \left.\operatorname{dist}\left(w_{1, i-1}, w_{1, j-1}^{\prime}\right)+p * \operatorname{dist}\left(w_{i, i}, w_{j, j}^{\prime}\right)\right)
\end{aligned}
$$

with $\mathrm{w}_{n, m}$ being the substring beginning at the $n^{\text {th }}$ character and finishing after the ${ }^{\text {th }}$ character of the word $\mathrm{w}$,

$$
\begin{aligned}
\operatorname{dist}(x, y) & =1 \text { if } x=y \\
& =0 \text { if } x \neq y
\end{aligned}
$$

and

q cost of the insertion/deletion of one character p cost of the substitution of one character by another.

Gencrally, a substitution is comsidened as a deletion followed by an insertion, thes $\mathrm{p}=2 \mathrm{c}$. Wo apply this algorithen to aach stem $R$, oblatinced after the deletion of the relational sulfix, that had not been found as a stem of a nome. Buth, wo add the constraint that $R$ and the nomm must. share the same two first characters, i.e. the substring computed begin at character 3. We only retain couples composed of an acljective and a noun with a Levenshtein's weighted equal to 3 (i.e. one substitution + one insertions). From these couples, we deduce new relational suffixes to be added to list of allowed sullixes. More precisely, we consider that such suflixes are allomorphic variants of the rolation suflixes. We also add new morphological rules. For example, for the couplo (hygiène, hygiénique), we add the suffix - énique which is considered as an allomorph of the suffix -ique, and create the rule: [-énique +ène]. However, this mothod doesn't

\begin{tabular}{|c|c|c|}
\hline $\begin{array}{l}\text { Relational } \\
\text { Suffix }\end{array}$ & $\begin{array}{l}\text { Number of } \\
\text { allomorphs }\end{array}$ & $\begin{array}{l}\text { Number } \\
\text { of rules }\end{array}$ \\
\hline$-a l$ & 3 & 5 \\
\hline - aire & 4 & 8 \\
\hline-6 & 2 & 2 \\
\hline$-a l$ & 1 & 2 \\
\hline$-e r$ & 1 & 2 \\
\hline$-c u t$ & 1 & 3 \\
\hline$-i e n$ & 1 & 2 \\
\hline$-i c r$ & 1 & 2 \\
\hline$-i f$ & 2 & 6 \\
\hline$-i n$ & 1 & 2 \\
\hline$-i q u c$ & 8 & 18 \\
\hline$-i s t e$ & 1. & 1. \\
\hline -oire & 1 & 1 \\
\hline Total & 25 & 54 \\
\hline
\end{tabular}
retrieve RAdj built from non antonomons bases of noun classes such as cour/card (heart/card), nor from Jabtin nown bases such as pere/pater. (father/pater), ville/urb (town/urb).

Wo check manually the rules obtained and
Figure 1: Number of variants and rules by relational suflix

added to the list of exceptions the wrong derivations obtianed. Table 1 presents the number of rules retained and the number of variants for each suffix.

\section{Term Extractor}

First, we prosent the term extractor chosen then, the modifications perform to enable the? a]pplication of the derivational rules.

\subsection{Initial Term Extractor}

ACABI'L' (1)aille, 1996), the term extrantor used for this experinent eases the task of the torunnologist by proposing, for a given corpus, a list of candidate terms ranked, fiom the most jep)resentative of the domain to the least using a statistical score. Candidate terms which are extracted from the corpus belong to a special type of cooccinrences:

- the cooccurrence is oriented and follows the linear order of tihe text;

- it is composed of two lexical units which do not bolong to the class of functional words such as prepositions, articles, etc.;

- it matches one of the morphosyntactic patterns of what we will call "base terms", or one of their possible variations.

'The paticrns for base torms are:

Noun1 Adj cmballage biodégradable (biodegradable package)

Noun1. Noun2 ions calcium 
Noun1 (Prep (Det)) Noun2 ions calcium (calcium ion) protéine de poissons (fish protein), chimioprophylaxie an rifampine. (rifampicin chemoprophylaxis)

Noun1 à Vinf viandes à griller (grill meat)

These base structures are not frozen structures and do accept several variations. Those which are taken into account are:

1. Inflexional and Internal morphosyntactic variants:

- graphic and orthographic variants which gather together predictable inflexional variants: conservation de produit (product preservation), conservations de produit (product preservations), or not: conservation de produit$s$ (products preservation) and case differences.

- variations of the preposition: chromatographie en colonne (column chromatography). chromatographie sur colonne (chromatography on column);

- optional character of the preposition and of the article: fixation azote (nitrogen fixation), fixation d'azote (fixation of nitrogen), fixation de l'azote (fixation of the nitrogen);

2. Internal modification variants: insertion inside the basc-term structure of a modifier such as the adjective inside the Noun1 (Prep (Det)) Noun2 structure: lait de brebis (goat's milk), lait cru de brebis (milk straight from the goat);

3. Coordinational variants: coordination of base term structures: alimentation humaine (human diet), alimentation animale et humaine (human and animal diet);

4. Predicative variants: the predicative role of the adjective: pectine méthylée (methylate pectin), ces pectines sont méthylées (these pectins are metylated).

The corpus is tagged and lemmatized. The program scans the corpus, counts and extracts collocations whose syntax characterizes base-terms or one of their variants. This is done with shallow parsing using local grammars based on regular expressions (Basili et al., 1993). These grammars use the morphosyntactic information associated with the words of the corpus by the tagger. The different occurrences are grouped as pairs formed by lemmas of the candidate ter$\mathrm{m}$ and sorted following an association measure which takes into account the firequence of the cooccurrences.

\subsection{Term Extractor modifications}

The identification of relational adjective takes place after extraction of the occurrences of the candidate terms and their syntactic variations. The algorithm below resumes the successive steps for identifying relational adjectives:

1. Examine cach candidate of Noun Adj structure;

2. Apply a transformational rule in order to generate all the possible corresponding base nouns. We added morphosyntactic constraints for some suffixes, such as for the suffix -er, that the identified adjective is not a past-participle;

3. Search the set of candidate terms for a pair formed with Noun1 (identical between a Noun1. (Prep (Det)) Noun2 and a Noun1 Adj structures) and Noun2 generated fiom step 2.

4. If step 3 succeeds, group the two base structures under a new candidate torm. Take out all the Noun Adj structures owing this adjective from the set of Noun Adj candidates and rename them as a Noun RAdj structure.

In Step 2, morphological rules generate one or several nouns for a given adjective. We generate a noun for each relational suffix class. A class of suffixes includes the allomorphic variants. This overgeneration method used in information retrieval by (Jacquemin and Tyoukermann, 1999) gives low noise because the base noun must not only be an attested for in the corpus, but must also appear as an extension of a head noun. For example, with the adjective ionique (ionic), we gencrate both ionie (ionia) and ion (ion), but only ion (ion) is an attested form; with the adjective gazeux (gaseous), the noun forms gaz (gas) and gaze (gauze); are gencrated and the two of them are attested; but, the adjective gazeux (gaseous) appears with the 


\begin{tabular}{|c|c|c|c|}
\hline $\begin{array}{l}\text { Number of occurrences } \\
\text { base structures }\end{array}$ & 1 & $\geq \overline{2}$ & Total \\
\hline Nom1 Prep (I)et) Nom2 & 17232 & 5949 & 231.81 \\
\hline Nom Adj & 12344 & 4778 & 17122 \\
\hline Nom à Vinf & 203 & 16 & 219 \\
\hline Total & 29912 & 10895 & 40807 \\
\hline
\end{tabular}

Figne 2: Quantitative datia on base structures

noun échange (exchange) which is paraphrased in the corpus by échange de gaz (gas exchange) and not by échange de gaze (gauze exchange). For adjectives with a noun function, as for example problème technique (technical problem) and probleme de technique (problem of technices), wo have accepted that a candidate term could share several base structures: one of type Nom1 (Prej) (Det)) Nom2 and another of type Nomil Adj. No computation is meeded to see that Nomn2 as Nomn2 and Adj share the same lemmil.

\section{$5 \quad$ Results and Evaluation}

Our corpus, called [ $\Lambda$ GRIC], is made up of 7272 abstracts $(430000$ words) from French texts in the agricalture domain and extracted from PASCAL. We used the Brill part-of-Speech Tagger (Brill, 1992) trained for lirench by (Leconte: and Paroubek, 1996)) and the lemmatizer developed by F. Namer (Toussaint et al., 1998).

\subsection{Quantitative results}

Table 2 resumes the number of base structures extracted from [AGRIC] corpus. From these base structures, 395 groupings were identified. The linked presence of nom phrases of which the extension is fulfilled either by a relational adjective, or be a prepositional phrase the mumber is rare - a little bit more than $1 \%$ of the total of occurrences-- But, these groupings allow us to extract from the numerous hapax . more than $70 \%$ of the total of occurencescandidates which, we presume, will be highly denominative and to increase the number of occurrences of a candidate term. The number of relational adjectives which have been identificd is 129: agronomique (agronomical), alimentaire (food), arachidier (groundnut), aromatique (aromatic), etc.

\subsection{Linguistic Precision}

We checked the linguistic accuracy of the 395 structural variations which group a Noun1. Prep (Det) Nom2 structure and a Nom1 RAdj structure. Reported errors concen 3 incorrect groupings due to the homograplyy, and the non homonymy, of the adjective and the noun: fin (thin (Adj)/end (Noun)), couran$t$ (ordinary $(A d j) /$ current (Noun)), potenticl (potential). 'This lead us to a linguistic precision of more than $99 \%$ in the identification of relational adjectives. As a matter of comparison, (Jacquemin, 1999) obtained a precision of $69,6 \%$ for the Nom to Arlj morphosyntactic variations calculated according to the morphological families produced by a stemming algorithm applied to the MUIJFXX' lexical database (MULIJYXT', 1998) on the same. french corpuss [AGRIC].

\subsection{Informative Precision}

The thesaurus (AGROVOC, 1998) is a taxomomy of about 15000 terms associated with synonyms in a SGML format, which learls to 25964 different terms. AGROVOC is used for indexing with datia fiting agricultural retrieval systems and indexing systems. Wo made two comparisons with AGROVOC: we first checked whether these $R \Lambda d j R$ were really part of terms of it and second, we compared the candidate terms extracted with a RAdj with its torms. Wo considor that the presence of the RAdj in AGROVOC confirms its informative character, and that the presence of a candidatio term atitests its terminological value.

\subsubsection{Relational adjectives alone}

From the 124 correct RAdj, 68 appear insido terms of the thesaurus in epithetic position, and 15 only under their noun form in an extension position, for example arachidier (groundnut) does not appear but arachide is used in an extension position. Moreover, among the 124 adjectives, 73 appear in AGROVOC under their noun term as uniterms. The adjectives which are not present in the thesaurus in an extension position under either their adjectival or nom form are $11 \mathrm{in}$ mumber. So $93 \%$ of them are inded highly informative. 


\subsubsection{Candidate terms with a relational adjective}

Pour 9 AdjR belonging to AGROVOC, we compute the following indexes:

$\mathbf{T}_{A}$ the number of terms in AGROVOC in which the relational adjective appears in an epithetic position, i.e. the terms of Noun RAdj structure. For example $\mathrm{T}_{A}=15$ for the adjective cellulaire (cellular) because it; appears in 15 terms of AGROVOC such as différenciation cellulaire (cellular differenciation), division cellulaire (cellular division).

$\mathbf{T}_{N}$ the number of terms in AGROVOC in which the noun from which has been derived the relational adjective appears inside a prepositional phrase, i.e. the terms of Noun1 Prep (Det) Noun $R A d j$ structure. For example $\mathrm{T}_{N}=4$ for the noun collule (cell) because it appears in 4 terms of $\mathrm{A}$ GROVOC such as banque de cellules (cell bank), culture de cellules (culture of cells).

$\mathbf{C}_{A}$ the number of candidate terms of Noun RAdj structure. For example, $\mathrm{C}_{A}=61$ for the adjective cellulaire (cellular) because it appears in 61candidate terms such as acide cellulaire (cellular acid), activité cellulaire (cellular activity), agrégat cellulaire (cellular aggregate).

$\mathbf{C}_{N}$ the number of candidate terms of Noun1 Prep (Det) Noun Ridj $_{\text {structure. For exam- }}$ ple $\mathrm{C}_{N}=58$ for the noun cellule (cell) because it appears in 58 candidate terms such as $A D N$ de cellule (cell DNA), addition de cellules (cell addition).

Then, for each candidate term of $\mathrm{C}_{A}$ and $\mathrm{C}_{N}$, we checked for their presence in AGROVOC. The only matches that we have accepted are exact matches. With this comparison, we obtained the following indexes:

a the number of candidate terms of Noun RAdj structure found in AGROVOC under the Noun RAdj structure.

b the number of candidate terms of Noun RAdj structure found in AGROVOC under the Noun1 Prep (Det) Noun $R A d j$ structure.

\begin{tabular}{lrr}
\hline & Noun RAdj & N1 Prep (Det) \\
\hline Precision & 0,34 & $0, \mathbf{0 4}$ \\
Recall & $\mathbf{0 , 4 6}$ & $\mathbf{0 , 1 4}$ \\
\hline
\end{tabular}

Figure 3: Averages of precisions and recalls

c the number of candidate terms of Noun1 Prep (Det) Noun ${ }_{R A d j}$ structure found in AGROVOC under the Noun RAdj structure.

$\mathrm{d}$ the number of candidate terms of Noun1 Prep (Det) Noun $_{R A d j}$ structure found in AGROVOC under the Noun1 Prep (Det) Noun $_{R A d j}$ structure.

These indexes allow us to compute precision $P$ and recall $R$ for each Noun RAdj structure and each Nounl Prep (Det) Nom RAdj $_{j}$ structure with the help of the following formula:

$$
\begin{gathered}
P_{\text {NounRAdj }}=\frac{(a+b)}{C_{A}} \\
P_{\text {NounPrep }(D c t) N_{\text {oun }} \text { RAdj }}=\frac{(c+d)}{C_{N}} \\
R_{\text {NounRAdj }}=\frac{(a+b)}{T_{A}} \\
R_{N o u n P r e p(D e t) N o u n_{R A d j}}=\frac{(c+d)}{T_{N}}
\end{gathered}
$$

The averages of precision and recall for the two structures are summarized in table 3 . This comparison of the average of precision computed shows that candidate terms with a Noun RAdj structure are 10 times more likely to be terms than their equivalent in Nounl Prep) (Det) Noun $R A d j$. The analysis of the average of recall is also impressive: it is generally difficult to obtain a recall superior to $25 \%$ when comparing candidate terms extracted from a corpus and a thesaurus of the same domain (Daille et al., 1998). The average of recalls obtained thanks to the identification of RAdj shows that nearly half of the terms built with the defined RAdj are identified. These good values of precision and recall have been obtained on linguistic criteria only without taking into account frequency.

\section{Conclusion}

The method proposed in this study to acquire morphological rules firom corpora in order to recover derivational term variations trough a term extractor and identify relational adjectives 
shows an excellent precision. We have also proved that noun phrases including a $R \Lambda d j$ aro far more informative than theis: equivalent, in Noun1 Prep (Det) Nom RAdj $_{\text {structure. We still }}$ have to write the program whose task will be to merge new morphological rules acquired from another corpus with the existing ones.

\section{Teferences}

S. Abney. 1991. Parsing with chunks. In R. Berwick and C. Tenny, oditors, PrincipleBase Parsing, pages 257-278. Kluwer Academoc: Publishers.

AGROVOC, 1998. AGROVOC - Multilingual Agricultural Thesaurus. Foorl and $\Lambda$ gricultural Organization of the Unitexl Nations. httip://www.fiao.org.

Roberto Basili, Maria 'Ieresa Pazienza, and Paola Volardi. 1993. Accuisition of Selectional Patterns in Sublanguauges. Machine Tranlation, 8:175 201.

Didier Bourigault. 1992. Surfice graunmatical analysis for the extraction of terminological noun phrases. In COJING'g\%, pages 977 981, Nantes, Fiance.

Erric Brill. 1992. A simple rule-based part of specch tagger. In $A N I P^{\prime \prime} 92$, pages 152-155, Trento, march.

Bóatrice Daille, Eric: Gantssier, and Jean-Marc: langé. 1998. $\Lambda 11$ evaluation of statistical scores for word association. In Jonathan Ginzhurg, Zurah) Khasidashvili, Carl Vogel, Jean-Jaccuess Lévy, and linric: Vallduvi, editors, The Tblisi Symposinm on Logice, Language and Computation: Selected Papers, pages 177 188. CSLI Publications.

Béatrice Daille. 1996. Study and implementiation of combined techniques for antonatic extraction of terminology. In Judith I. Klavans and Philip Resnik, oditors, The Balancing Act-Combining Symbolic and Statistical Aq)proaches to Language, chapter 3, pages $28-49$. MIT l'ress.

Sophie David and P. Plante. 1990. Le progiciel termino: De la nócessité d'une analyse morphosyntaxique pour le dépouillennent terminologicque des textes. In $I C O$, volume 2.

J. Dubois. 1962. Rtude sur la dérination suffixale en Franchais moderne et contemporain. Larousse, Paris.

Anne Guyon. 1993. Les addjectifs relationnels arguments de noms prédicatifs. Ph.D. thesis, Université Paris 7.

Ficlelia Ibokwe-Sanjua. 1998. Teminological variation, a mean of identifying research topics from texts. In COLING-ACL'98, volumo 1, pages 564 570, Montral, Canada.

Christian Jacquemin and Evelyne Troukermann. 1999. $\mathrm{N}_{\mathrm{p}}$ for term variant extraction: Synergy between morphology, lexicon and syntax. In T. Stralkowski, editor, Natural Language Processing and Information Retricval. Kluwer, Boston, M $\Lambda$.

Christian Jaced1emin. 1999. Syntagmatic and Paradigmatic Representation of Term Variation. In $A C L 99$, University of Maryland.

J. Justeson and S. Kati. 1995. Technical terminology: Some linguistic propertios and an algorithen for iclentification in text. In Journal of Linguistic Engineering, volume 1.

Josette Lecomte and Patrick Paroulsek. 1996. Ie catégoriseur d'eric brill. mise en cenvre de la version entrancéc à l'inalf. 'Jechnical report, CNRS-INALT:

V.I. Levenshtein. 1966i. Binary codes capable of correcting deletions, insertions and reversals. Sov. Phiys.-Dokl., 10(8):707 710.

Judith Levi. 1978. The syntax and the semanlices of complex nominals. Acarlenic P'ress, Tomelon.

A. Mélis-l'uchulu. 1991. Les adjectifs dénominaux : des adjectifs de "relatious". lextique, 10:33 60.

Aurder Mikheev. 1997. Automatic rule induction for unknown-word gnessing. Computertional Linguistics, 23(3):405 423 .

Anne Monccanx. 1993. Ja formation des noms composés de structure NOM ADJECTIF. Thèse de doctorat en linguistique théorique et formelle, Université de Marne la Vallée.

MUL'TEXT', 1998. Jaboratoire Parole of Ian1gakge. htt t] $): /$ www.lpl.univ-aix.fj:

Yamnick Toussaint, Fiametta Nanner, Bćatrice Jaille, Christian Jacequemin, Jcan Royanté, and Nabil Hathout. 1998. Une approche linguistique et statistique pour l'analyse de l'information en corpus. In TALN'SB, pages 182-191. Paris.

R.A. Wagner and M.J. Fisher. 1974. The? string-to-string correction problem. Jounnal of the Association for Computing Macthinery, 21.(1):168 173 . 